\title{
A Study on How to Support Small and Medium-Sized Businesses for the Promotion of the Digital Outdoor Advertising Industry \\ 디지털 옥외광고산업 진흥을 위한 중소사업자 지원
}

방안 연구

- 전문가 심층 인터뷰를 중심으로 -

Won Bae $\mathrm{Ji}^{1}$

지원배 ${ }^{1}$

${ }^{1}$ Professor, Division of Advertising, PR, \& Visual Communication, Hanshin University, Korea,

$7321 @$ daum.net

\begin{abstract}
This study conducted in-depth interviews with experts in order to suggest support measures suitable for the New Normal environment, and measures to promote the digital outdoor advertising industry to small and medium-sized outdoor advertising businesses whose economic situation has deteriorated due to COVID-19. The results of the analysis were as follows. First of all, small and medium-sized outdoor advertising businesses are experiencing difficulties due to COVID-19, so government support is urgently needed. Second, although small and medium-sized outdoor advertising businesses are aware of the transition of the digital outdoor advertising industry, they demanded support and fostering policies that reflected the position of existing small and medium-sized businesses. Third, support for the development of new materials and new media, education on digital outdoor advertising, and the provision of opportunities to participate in selecting operators of digital outdoor advertising for public purposes were suggested. The suggestions were made for a short-term support plan targeted small and medium-sized businesses to promote the digital outdoor advertising industry. As long-term support measures, it was proposed to ease regulations on related laws for the development of new technologies, to ease public digital outdoor advertising companies' participation in bidding, and to cooperate with large business operators for new media and new technologies.
\end{abstract}

Keywords: Digital Outdoor Advertising Industry, Small Business Support, Outdoor Advertising, Advertising Industry Promotion, Advertising Education

요약: 본 연구는 코로나19로 인해 경제 상황이 악화된 옥외광고 중소사업자에게 뉴노멀(New Normal) 환경에 맞는 지원책과 디지털 옥외광고산업 진흥 방안을 제시하기 위해서 전문가 심 층 인터뷰를 실시하였다. 분석결과 다음과 같이 나타났다. 우선 코로나 19 로 인해 옥외광고 중 소사업자들은 어려움을 겪고 있어 정부의 지원이 시급하였다. 둘째, 디지털 옥외광고산업의 전환을 인식하고 있으나 기존 중소사업자의 입장을 반영한 지원과 육성 정책을 요구하였다. 셋째, 디지털 옥외광고산업 진흥을 위한 중소사업자 단기적 지원 방안으로 신소재·신매체 개

Received: September 18, 2021; $1^{\text {st }}$ Review Result: November 5, 2021; $2^{\text {nd }}$ Review Result: December 24, 2021 Accepted: January 29, 2022 
발 지원, 디지털 옥외광고 교육, 공공목적 디지털 옥외광고물 운영사업자 선정 참여 기회 제 공이 제안하였다. 장기적인 지원 방안으로 신기술 개발을 위한 관련 법 규제 완화, 공공 디지 털 옥외광고물 사업자 입찰 참여 방식 완화, 신매체·신기술 전환을 위한 대형사업자와의 업무 제휴 등을 제안하였다.

핵심어: 디지털 옥외광고산업, 중소사업자 지원, 옥외광고, 광고산업 진흥, 광고교육

\section{1. 서론}

최근 코로나19로 인한 경기침체로 광고산업의 전망이 어둡다. 특히, 옥외광고시장의 2020 년 광고비는 9,899억 원으로 2019년 1조2,568억 원 대비 $21.2 \%$ (약 2,669억 원) 감소한 것으로 나타났으며, 코로나19 영향을 가장 크게 받은 광고 매체로 평가되고 있다[1]. 광고 매체별 광고 집행이 감소하는 것은 물론 광고 예산의 축소로 인해 전반적인 구조 변화가 가속될 것으로 전망되고 있다. 옥외광고산업의 경우 영세 소상공인들을 대상으로 생활 간판 위주로만 운영하던 업체들도 최근 자영업의 침체로 인해 간판 주문이 대폭 줄어들면서 어려움을 격고 있다. 옥외광고산업 관계자들은 광고 시장의 다변화로 새로운 분야의 개척을 통해 현재의 어려움 상황을 극복하기 위한 다방면의 노력을 기울이고 있다. 이들은 대형자본에 의한 구조를 탈피하고 광고 업계 내부의 지나친 저가 경쟁으로 인해 경쟁력을 약화하는 문제를 탈피하기 위한 자구책 마련과 함께 디지털 기술을 접목한 옥외광고시장의 확장 등 변화에 대응하고 있다.

이처럼 코로나19 이후 뉴노멀 시대에 중소사업자들을 위한 디지털 옥외광고산업 진흥의 필요성 대두되고 있다. 정보통신기술(ICT)을 바탕으로 자동화와 지능화를 추구하는 4차 산업혁명 시대에 접어들면서 광고산업도 디지털 기술을 바탕으로 진화하고 있다. 특히 코로나19로 인해 언택트 중심의 디지털 옥외광고산업이 빠르게 변화하고 있다. 디지털 옥외광고시장이 발전하기 위해서는 중소사업자가 안정적으로 활동할 수 있는 거래환경 조성, 인프라 구축, 기술발전 지원, 교육 등 구체적인 지원체계가 필요하다.

따라서 본 연구에서는 옥외광고 중소사업자를 지원하고, 뉴노멀 시대에 적합한 디지털 옥외광고산업 발전 방안을 마련하기 위해서 기존 문헌연구와 관련 분야 전문가 심층 인터뷰를 실시하였다. 이러한 결과를 토대로 코로나19로 인해 경제 상황이 악화된 옥외광고 중소사업자들에게 뉴노멀 환경에 맞는 지원책과 디지털 옥외광고산업 진흥방안을 제시하고자 한다.

\section{2. 옥외광고산업 진흥 문헌연구}

\section{1 코로나19로 인한 옥외광고산업 위기와 변화}

국내 옥외광고 시장은 지속적으로 성장하고 있으나 코로나19 이후로 감소 추세가 나타나고 있다. 국내 옥외광고 시장 규모는 2019년 기준으로 1 조 2,568억 원으로 조사되었으나 코로나19 영향으로 옥외광고 시장은 2020년에는 9,899억 원으로 전년 대비 $20 \%$ 이상 크게 하락하였다. [표 1]에서 보는 바와 같이 매출규모에 있어서 전체적으로 감소하는 추세를 보이고 있다. 특히 서울시와 6대 광역시에 비해 지방 9개 도시의 
구성비가 더 감소하고 있는 것을 알 수 있고, 1 억에서 5 억 미만과 5 억에서 10 억 미만의 업체의 매출액이 줄어들고 있어 코로나19로 인한 옥외광고 중소사업자의 위기가 심각한 것으로 나타났다[2]. 2020년 광고산업조사(문화체육관광부)에 따르면 총 643개 옥외광고업체가 활동하고 있으나 이 중 1 인 4인 규모 업체가 438 개(전체의 $68.1 \%$ ), 9 인 이하까지 포함하면 $568 / 643$ 개(전체의 $88.3 \%$ )에 이르고 있으나 광고 취급액이 매우 미약한 실정이다[3].

[표 1] 옥외 광고비 현황

[Table 1] Outdoor Advertising Expenses

\begin{tabular}{c|c|c|c|c|c|c|c|}
\hline \multirow{2}{*}{} & \multicolumn{5}{|c}{} & \multicolumn{3}{c}{ 구성비(\%)액(백만 원) } \\
\cline { 2 - 7 } & 2019 년 & 2020 년(e) & 2021 년(e) & 2019 년 & 2020년(e) & 2021 년(e) \\
\cline { 2 - 7 } 주요 권역별 & $1,256,765$ & 989,906 & $1,007,713$ & 100.0 & 100.0 & 100.0 \\
\hline 서울 & 841,620 & 699,128 & 718,983 & 67.0 & 70.6 & 71.3 \\
\hline 6대 광역시 & 132,912 & 117,839 & 118,161 & 10.6 & 11.9 & 11.7 \\
\hline 9개도 & 282,234 & 172,939 & 170,569 & 22.5 & 17.5 & 16.9 \\
\hline 광고 매출액 규모별 & & & & & & 0.1 & 0.1 \\
\hline 1천만 원 미만 & 1,411 & 1,245 & 1,162 & 0.1 & 1.0 & 1.1 \\
\hline 1천만 1억 원 미만 & 9,868 & 9,557 & 10,736 & 0.8 & 5.7 & 6.0 \\
\hline 1억 5억 원 미만 & 64,193 & 56,555 & 60,442 & 5.1 & 4.6 & 4.6 \\
\hline 5억 10억 원 미만 & 51,645 & 45,049 & 46,364 & 4.1 & 88.6 & 88.2 \\
\hline 10억 원 이상 & $1,129,647$ & 877,501 & 889,009 & 89.9 & & \\
\hline
\end{tabular}

자료 : 과기정통부, KOBACO, 2020년 방송통신광고비 조사

옥외광고산업은 ' 16 년도 관련 법률의 개정으로 큰 패러다임의 변화를 맞이했다. 행정안전부는 정부 발의를 통해 '옥외광고물 등 관리법'을 '옥외광고물 등의 관리와 옥외광고산업 진흥에 관한 법률(이하 ‘옥외광고물법')'로 개정하였다. 이는 정부가 옥외광고를 단순히 ‘규제'의 대상이 아니라 '진흥'이 필요한 산업으로 인식했기 때문이다. 특히 개정된 '옥외광고물법'에서 눈에 띄는 점은 바로 '디지털'이라는 용어가 새롭게 등장했다는 것이다. 디지털이라는 개념이 옥외광고 법령에 전혀 없었던 것은 아니나, 기존에는 '빛이 점멸하거나 동영상 변화가 있는 전광류 광고물'이라는 개념으로 LED 또는 $\mathrm{LCD}$ 에 한정해 사용을 허용했다. 그러나 개정된 법률에서는 디지털이라는 용어가 단순히 아날로그 옥외광고판을 디지털 패널로 교체하는 수준이 아니라 옥외광고산업 자체를 디지털 기반으로 변화시킨다는 취지가 담겨져 있다. 이러한 변화는 단순히 광고물의 외형뿐만 아니라 기존의 아날로그 산업 생태계가 디지털 트랜스포메이션(Digital Transformation)을 통해서 디지털 기반의 새로운 생태계로 탈바꿈하는 과정을 의미한다. 또한 광고매체의 판매에 있어서도 최근 인터넷 광고의 판매방식(RTB, 프로그래매틱 바잉 등)을 적용하고자 하는 움직임이 있다[4].

글로벌 플랫폼 기업이 독점 속에서 디지털 옥외광고산업 시장의 발전을 위해 신유형 광고 영역의 확장 및 옥외광고 중소사업지 지원에 대한 제도적 기반 마련이 시급하다. 최근 새로운 시장 개척을 위해 디지털 기술 및 장비 투자는 물론 경쟁력 강화를 위해 
택시, 인테리어, 엘리베이터 등 다양한 시장과의 연계를 통해 확장하려고 한다. 예컨대 교통수단을 이용한 택시 광고의 한 유형이 택시 표시등 광고는 주요 선진국에서 도입된 사업으로 디지털을 활용한 새로운 옥외매체로서의 가능성을 발견하였다. 또한 3D 프린터, 평판 UV 프린터를 통해 다양한 수요 맞춤형 광고물 제작에 힘을 기울이고 있고, 전광판 업체들 사이에서도 경쟁력 강화를 위해 동영상, 정지영상까지 표출할 수 있는 전광판을 제작하여 변화를 쾌하고 있다. 이처럼 옥외미디어의 디지털화는 코로나19 시대에 이후 더욱 가속화될 것으로 전망된다. 유동인구 데이터, 모바일 데이터, 교통 정보 등의 공공 데이터를 활용한 광고 상품들이 전개될 것이며, $\mathrm{OOH}$ 전광판과 모바일이 연동된 광고 집행도 다양하게 시도될 것으로 보인다. 디지털 사이니지를 이용해 공공데이터를 개방하는 지방자치단체들이 하나둘씩 늘어나고 있다. 디지털 사이니지는 주로 트레인 채널, 메디 캐스터, 마케팅 데이터를 축적할 수 있는 자동판매기 등에 활용되고 있는데, 공공데이터를 비롯한 긴급 정보와 이벤트 정보, 관광지 정보 등이 중심이 되어 게시되고 있어 이러한 공공데이터 전달과 함께 기업의 광고도 함께 이루어지면 효과가 높다. 자유표시구역 내 LED 확대 등으로 빌보드의 전광판 광고가 전년 대비 상승했고, 쇼핑몰과 아파트 LCD도 함께 성장하는 등 코로나19 상황에서도 지속 성장하는 미디어가 될 것으로 전망된다.

\section{2 디지털 옥외광고산업 진흥과 중소사업자 지원 문헌연구}

옥외광고산업 진흥을 위해서 디지털 옥외광고산업 활성화가 필요하다는 의견이 많았다. 2010년 이후부터 광고주나 광고대행사 그룹의 인식변화가 기존의 옥외광고 방식에 대한 거부감으로 나타나 디지털과 같은 새로운 유형의 옥외광고를 제공해야 한다고 하였다[5]. 특히 스마트 광고산업에 있어서 디지털 사이니지 활성화 방향 모색이 필요한데 그러기 위해서는 디지털 광고의 법적 근거 마련과 정부 주도의 체계적인 진흥책 마련이 필요하다[6]. 한광석(2014)의 연구에서는 국내 옥외광고 진흥을 위해서 '브레인웨어(Brainware), ‘콘텐츠 생산(Software)', '기반시설과 인프라(Hardware)' 세 가지 차원에서 세부적인 인프라 구축이 필요하다고 하였다[7]. 결국 디지털 미디어 시대 신기술을 활용한 옥외광고 지원 방안이 필요[8]하며, 광고산업 진흥 차원에서도 신유형 광고 영역 확장 및 기반 마련을 위한 제반사업과 중소형 광고업체 지원이 필수적이다[9].

옥외광고 중소사업자의 연구도 있었다. 박현(2018)은 옥외광고 중소사업자 관점의 옥외광고산업 정책개선에 대한 의견을 알아본 결과 불법 광고물에 대한 실효성 있는 관리방안, 중소기업 지원 및 신기술 광고물의 점진적 확대, 공공 안정성 확보를 위한 법제도 개선, 동반성장과 스타트업 육성을 위한 정책적 개선이 필요하다고 하였다[10]. 이희복, 차유철, 이시훈(2015) 연구에서는 디지털 옥외광고산업 진흥에 앞서 전자게시대 도입에 따른 옥외광고 중소기업 지원 방안을 제시하였다[11]. 그 결과 단기적으로 중소기업 교육과 디지털 기술 수용에 의견과 함께 장기적으로 정부광고를 비롯한 공공영역의 광고를 옥외광고 중소기업에게 우선 배정할 수 있도록 제도적 장치가 필요하다고 하였다. 그러나 기존 연구는 옥외광고 산업 전반에 관한 연구이거나 디지털 옥외광고산업 중 전자게시대에 한정한 연구여서 좀 더 심도 있는 연구가 필요하다. 따라서 본 연구에서는 코로나19 이후 어려움을 겪고 있는 옥외광고 중소사업자를 위해 디지털 광고산업 진흥을 위한 옥외광고 중소사업자 지원 방안에 대해 심층적으로 분석하고자 한다. 


\section{3. 연구문제 및 연구방법}

\section{1 연구문제}

본 연구는 코로나 19 로 인해 경제 상황이 악화된 옥외광고 중소사업자들에게 뉴노멀 환경에 맞는 지원책과 디지털 옥외광고산업 진흥방안에 관한 연구이다. 현재 새로운 디지털 옥외광고 활성화를 위한 진흥 방법에 대한 필요성과 정부 주도의 협력 방안을 논의할 시기이다. 그러기 위해서는 디지털 옥외광고산업 진흥 정책 결정 및 추진에 있어 민관협력이 필요하며, 특히 중소사업자들의 디지털 옥외광고 전환을 위해 실효성 있는 지원 방안이 모색되어야 한다.

옥외광고 중소사업자 육성을 위한 여러 가지 방안들이 모색되고 있으나 아직 구체적인 대안을 제시하지 못한 상황이며, 디지털 전환에 있어 옥외광고 중소사업자들이 느끼는 제약 요인을 파악하지 못하고 있다. 따라서 본 연구에서는 전문가 심층인터뷰를 통해 옥외광고 중소사업자들이 원하는 디지털 옥외광고산업 지원 방안을 알아보기 위해 다음과 같은 연구문제를 제시하고자 한다.

[연구문제 1] 코로나19 이후 옥외광고산업 현황 및 미래 전망에 대해서 옥외광고 전문가들은 어떻게 생각하고 있는가?

[연구문제2] 디지털 옥외광고산업 진흥 필요성과 디지털 옥외광고산업 정책 개선안에 대해서 옥외광고 전문가들은 어떻게 생각하고 있는가?

[연구문제3] 옥외광고 전문가들은 디지털 옥외광고산업 진흥을 위해서 정부 차원의 옥외광고 중소사업자 지원방안이 무엇이라고 생각하는가?

\section{2 연구방법}

옥외광고산업 발전 및 중소사업자 지원 방안에 대해서 알아보기 위해서 옥외광고 전문가 심층 인터뷰(In-Depth Interview)를 실시하였다. 심층 인터뷰는 2021년 7월 20일부터 8월 13일 사이에 수행되었으며, [표 2]와 같이 10년 이상의 옥외광고관련 협회 관계자 3 명, 광고관련 연합회 관계자 1 명과 옥외광고산업 연구를 수행한 학계 4 명 등 총 8 명을 대상으로 수행되었다.

심층 인터뷰는 옥외광고관련 문헌 및 한국옥외광고센터 관계자 논의를 통해 현재 옥외광고산업진흥 및 중소사업자 지원에 필요한 의제 다섯 가지를 추출하였다[7-11]. 참고문헌 자료와 함께 전문가들과 1) 코로나 이후 옥외광고산업 현황 및 미래 전망, 2) 디지털 옥외광고산업 진흥 필요성, 3) 중소사업자 시각에서의 디지털 옥외광고산업 정책 개선안, 4) 정부 차원의 디지털 옥외광고산업 진흥을 위한 중소사업자 지원 방안, 5) 옥외광고 중소사업자 교육 내용에 대해서 심층적으로 인터뷰 한 후 분석을 실시하였다. 본 심층 인터뷰를 수행하기 위해서 1차로 사전에 설계된 인터뷰 가이드를 설명하고, 충분한 시간을 주어 응답자가 자유롭게 의견을 개진하였다. 1 차 인터뷰 이후 전문가들을 일주일 동안 자신의 생각을 정리하여 인터넷 메일로 의견을 개진하였다. 이처럼 심층인터뷰 결과는 온라인을 통해 질적 자료를 수집하는 네쓰노그라피(netnography: net+ethnography) 방법을 활용하였으며, 전문가 자료를 분석하여 공통된 특징과 차이점이 구분하여 연구결과를 기술하였다[12][13]. 
[표 2] 전문가 심층인터뷰 프로파일

[Table 2] Expert In-depth Interview Profile

\begin{tabular}{c|c|c|c}
\hline 대상 & 소속분야 & 직급 & 경력 \\
\hline 업계1 & 한국전광방송협회 & 부회장 & 서울시중구광고물심의위원 \\
\hline 업계2 & 한국전광방송협회 & 사무총장 & 한국광고대회 옥외광고 심사위원 \\
\hline 업계3 & 한국옥외광고미디어협회 & 전무 & 관련 분야 공무원 \\
\hline 업계4 & 한국광고총연합회 & 사무국장 & 경기방송 전략기회 부장 \\
\hline 학계1 & 상지대학교 & 교수 & 한국광고PR실학회 회장 \\
\hline 학계2 & 계명대학교 & 교수 & 한국광고학회 회장 \\
\hline 학계3 & 서원대학교 & 교수 & 한국OOH학회 연구이사 \\
\hline 학계4 & 한남대학교 & 교수 & 한국광고PR실학회 총무이사 \\
\hline
\end{tabular}

\section{4. 연구결과}

\section{1 [연구문제 1]의 연구결과}

코로나19 이후 옥외광고산업 현황과 미래 전망에 대해서 살펴본 결과 전문가들은 전체적으로 코로나19 이전에 비해 옥외광고시장이 침체되었다고 생각하였다. 정부정책의 사회적 거리두기 등으로 옥외광고 특성인 대면 영업이 불가하여 많은 옥외광고 중소사업자들이 도산과 파산의 위기에 처해 있고, 코로나19 이후 옥외디지털 전광방송광고의 경우 대형사업자와 중소사업자간의 빈익부 부익부의 격차가 심화되어 있음을 지적하였다. 중소사업자의 경우 상대적으로 더 큰 피해를 보고 있기에 옥외광고산업의 미래를 위해서 정부의 획기적인 개선과 지원이 필요하다고 하였다. 장기적으로 옥외광고산업이 발전하기 위해서는 영업하기 쉬운 환경 조성과 광고주의 선택을 받을 수 있도록 새로운 기술 도입이 필요하다고 하였다. 이상 정보 제공자의 구체적인 발언 내용을 제시하면 다음과 같다.

“코로나19 발생 이후 정부 정책인 사회적 거리두기 등으로 옥외광고의 특성인 대면 영업이 불가하여 상업광고를 할 수 있는 옥외광고매체의 $80 \%$ 정도는 백판(미게첨)인 상태로 있어 업계는 도산과 파산 위기에 처해 있습니다. 현재의 옥외광고시장 등 옥외광고산업은 획기적인 개선과 지원 없이는 극복하기 어려운 상황에 처해 있다고 할 수 있어요. 장기적으로 영업하기 쉬운 환경의 조성과 매체의 개발이 등이 선행되어야 합니다.”(업계 3)

“코로나19 상황으로 전반적인 광고산업이 침체되고 있는 상황에서 옥외광고산업은 디지털 전환으로 명맥을 간신히 유지 하고 있는 상황입니다. 여러 제도적 문제들 때문에 사업자들은 어려움을 겪고 있습니다.”(학계 4)

“사상 유례없는 코로나19 펜데믹으로 전 산업과 광고 분야가 영향을 받는 가운데 옥외광고산업도 커다란 변화를 맞고 있습니다. 특히 중소상공인 중심으로 한 전통적인 옥외광고는 그 피해가 크다고 하겠습니다."(학계 1)

“코로나19 이후 옥외광고산업은 전반적으로 침체 된 것은 사실입니다. 특히 옥외디지털전공방송광고의 경우는 오히려 코로나 19 로 인하여 빈익빈 부익부의 격차가 더 
심화되 중소형 옥외광고사업자의 경우 그 피해의 정도가 상대적으로 크지 않았나 싶습니다. 단기적으로 옥외광고산업의 전망을 밝지 않지만 과거 IMF 시기에도 옥외광고산업은 지향적으로 발전해왔습니다. 장기적으로 다각적인 시도와 변화에 대한 빠른 대처가 필요해요. 새로운 기술적 도입과 그에 맞는 진흥이 전제되기 위해서는 법령개정도 필요합니다.”(업계 2)

“코로나 19 의 직격탄을 맞는 것이 옥외광고산업이라는 생각을 했어요. 주변 상권을 보면 절반이 문을 닫았어요. 영세 옥외광고 사업자들에게 부정적인 영향이 크리라 생각해요. 단기적으로 어렵겠지만 장기적으로 디지털 사이니지, 표지자유구역 등 규제완화의 효과가 발휘된다면 소폭의 성장은 가능하다고 봐요.”(학계 2)

\section{2 [연구문제 2]의 연구결과}

중소사업자 관점의 디지털 옥외광고산업 진흥의 필요성에 대해서 전문가들은 현재 디지털 비중이 $50 \%$ 이상을 차지하는 상황에서 디지털 옥외광고는 4 차 산업혁명 등 시대를 반영한 자연스러운 변화라고 생각하였다. 다만, 업계에서는 디지털 옥외광고산업 진흥을 위해서는 새로운 디지털 미디어에 대한 기술적 차원의 진흥도 필요하지만 옥외광고산업자의 욕구를 반영한 진흥이 필요하다는 의견이 많았다. 2016년 옥외광고물법이 진흥을 위한 법으로 개정되었으나 디지털광고물이라는 용어만 들어갔을 뿐 시행령에서 구체적인 내용이 들어가지 않았다. 또한 중소사업자에 대한 보호장치 및 참여기회가 제도적으로 마련되어 있지 않아 대기업 및 언론사가 자본을 바탕으로 시장을 선점해 중소사업자는 오히려 힘든 시기를 겪었다. 진정한 옥외광고 중소사업자 육성을 위해서는 정부 차원의 자금지원과 기술 개발 공유 노력(정책)이 함께 선행되어야 한다.

옥외광고 중소사업자의 의견이 반영된 디지털 옥외광고산업 육성으로는 대기업, 언론사 위주의 사업자 선정 방식 개선, 공공기관 광고 집행 시 과도한 수수료 부과 개선, 디지털 전환에 대한 중소사업자 교육과 지원 등을 들었다. 특히 디지털 옥외광고산업 진흥을 위한 중소사업자 교육의 경우 디지털 환경에서 옥외광고 중소사업자가 생존할 수 있도록 디지털 연계 옥외광고 교육 프로그램이 재직자 중심으로 개설해야 한다고 하였다. 특히 디지털 연계 옥외광고 교육기관 시설이 제공 마련되어 기초과정(옥외광고물 법규의 이해, 불법광고와 광고 윤리, 옥외광고산업 동향 등)과 심화과정(최근 신기술을 활용한 옥외광고 사례, 디지털 광고 제작 및 관련 법규 교육 등) 형태로 구성되어야 한다고 하였다. 이상 정보 제공자의 구체적인 발언 내용을 제시하면 다음과 같다.

“지난해 코로나19 여파로 전 세계는 물론, 국내 각 산업의 패러다임이 디지털로 가속화되는 상황이며, 전체 광고시장에서 디지털 비중이 $50 \%$ 이상을 차지할 것으로 업계에서는 예상하고 있습니다. 특히 정부에서 추진하는 '디지털 뉴딜정책'을 통해 새로운 성장동력 창출에 고심하고 있는데, 옥외광고산업에 속해있는 사업자, 근로자들에게 이러한 디지털 트랜스포메이션 시대에 안정적으로 사업을 영위할 수 있도록 예산 및 교육 등 정부 정책 지원이 절실히 필요합니다.”(업계 4)

“법령은 물론이고 이제는 중소사업자들을 중심으로 오히려 특색있는 옥외광고를 개발하고 시행하려는 의지가 늘어나고 있다고 봅니다. 이러한 의지의 영향력은 '디지털 사업이 약진하고 있다'고 판단되며 디지털의 특색이 주로 직접적으로 소비자가 체험하는 형태로 변화한다면 활성화를 위한 좋은 방식이 될 것으로 생각됩니다.”(학계 3)

“2016년 옥외광고산업 진흥에 관한 법률 명칭 개정과 함께 디지털 광고물이 최초로 
도입되었으나 기존 생태계를 무너뜨리는 부작용을 초래했어요. 대기업 또는 대형 언론사의 부수 사업 거리로 자본과 권력으로 시장을 장악해 나가는 블랙홀 현상이 시장의 양극화를 급속하게 조성해 왔어요. 언택트 시장의 발현에 따른 디지털 옥외광고산업 진흥은 육성해야 하나 중소사업자들이 해결할 수 없는 분야를 정부 차원에서 자금지원과 기술의 개발 공유 방안을 적극적으로 마련해 주어야 해요.”(업계1)

“새로운 디지털 미디어에 대한 기술적 차원의 진흥이 아니라 광고 사업자에게 우선되는 광고산업의 진흥을 위해 관련 부서의 컨트롤 타워를 통해 옥외광고산업의 반향을 일관성 있게 추진해가는 것이 필요합니다"(학계 4)

“옥외광고물법에서 디지털 광고를 명시하였지만, 표시기준에 대해서는 기존의 아날로그 방식과 디지털 방식이 서로 공존하여야 한다고 생각합니다. 디지털 광고를 많이 보급한다면 디지털 소재를 만드는 기업이 발전하는 반면 대다수 옥외광고제작사업자는 일거리가 없어 몰락(도산, 파산)할 것입니다."(업계 3)

\section{3 [연구문제 3]의 연구결과}

디지털 옥외광고산업 진흥을 위한 정부 차원의 옥외광고 중소사업자 지원 방안에 대해서 살펴본 결과, 단기적으로는 신소재·신매체 개발 지원, 디지털 옥외광고 교육, 옥외디지털미디어 개발에 따른 마케팅 및 판매 지원, 디지털 전환에 대한 옥외광고 사업자 인식 조사 등이 필요하다고 하였다. 특히 업계에서는 국가 및 공공단체가 운영하는 공공목적 디지털 광고물 운영사업자 선정에 옥외광고 중소사업자들도 참여할 수 있도록 지원이 필요하다. 장기적으로는 새로운 사업 영역을 찾을 수 있도록 신기술 개발을 위한 관련 법규(네거티브 규제)를 완화하고 옥외광고산업 진흥을 위한 장기적인 신소재·신매체·신기술 사업 연구 지원이 필요하다고 보았다. 또한 소규모 중소사업자들의 역량으로는 해결할 수 없는 R/D 투자 사업과 시장분석 및 광고효과 분석, 디지털 영상표출 장비, 빛공해 방지를 위한 영향평가분석 등에 대한 사업자 지원 제도와 IT산업의 선도국 지위에 걸맞게 옥외광고기술을 해외시장에 수출 할 수 있는 플래트홈 운영사업지원 제도 마련 등 산학관의 유기적인 협업이 필요하다고 하였다.

그러나 기존의 옥외광고 사업자들의 의견이 반영된 디지털 옥외광고산업 진흥이 필수적이어서 중소사업자의 막연한 기대가 아닌 중장기적 관점에서 접근이 필요하다. 즉 단기적으로 옥외광고 중소사업자에게 아날로그 방식과 디지털 방식이 상호 공존할 수 있는 제도적 지원이 필요하며, 장기적인 관점에서 산학협력 기술 및 서비스 개발과 옥외광고 중소사업 연합을 통한 경쟁력 확보 등이 필요하다. 이상 정보 제공자의 구체적인 발언 내용을 제시하면 다음과 같다.

“우선 단기적으로 국가 및 공공단체가 운영하는 공공목적 디지털 광고물 운영사업자를 선정함에 있어 소규모 광고사업자들이 진입할 수 있도록 일정 물량의 의무 배정 또는 입차 제도의 개선이 필요해요 두 번째로 옥외디지털전광판을 활용한 지방 자치단체가 선정한 우수중소기업 제품 판매 마케팅 지원 및 특산물 주문 판매에 따른 지원도 필요합니다. 장기적으로 소규모 중소사업자들의 역량으로 해결할 수 없는 $\mathrm{R} / \mathrm{D}$ 투자 사업과 시장분석 및 광고효과 분석 등 중소사업자 지원 제도와 옥외광고기술을 해외시장에 수출할 수 있는 운영사업지원 제도 등이 필요합니다."(업계1)

“단기적으로 실제 디지털 $\mathrm{OOH}$ 에 적용될 수 있는 기술과 이를 규제샌드박스로 허용해 시장의 크기를 키워가는 노력이 필요합니다. 아울러 옥외광고 자유표시 구역과 같이 
옥외광고산업을 진흥시킬 새로운 정책이 진행되어야 합니다. 장기적으로 매력적인 매체로 디지털 $\mathrm{OOH}$ 를 널리 알리고, 관련한 자원을 확보하고 정책을 만들어 성장을 이끌어가야 합니다. 법과 제도의 관점도 포지티브에서 네거티브로 과감한 규제 완화가 있어야 지속가능한 발전이 있습니다."(학계 1)

“단기적으로 옥외광고산업 사업자들에게 디지털 전환에 대한 인식, 대응전략, 정부지원 등 현황 실태파악이 필요합니다. 이러한 실태파악을 통해 나온 결과를 토대로 디지털 미디어 시대 신기술 등을 활용한 옥외광고 지원 방안, $\mathrm{AR}, \mathrm{VR}$ 등을 활용한 콘텐츠에 대한 기술지원 등이 필요합니다."(업계 4)

“장기적으로 산학협력의 기술, 서비스 개발이 필요합니다. 정부가 재원을 마련하고 대학교 연구소와 중소사업자와 협력해서 디지털 옥외광고 서비스를 지역단위로 개발하는 것에요. 성과가 좋으며 전국단위 서비스는 중소조합을 만들어 경쟁력을 높일 수 있습니다."(학계 2)

“단기적으로 디지털 광고물의 변경 및 신규 표시를 위한 초기 설치 투자비를 정부차원의 지원과 시·도에서 지정한 옥외광고물 표지 특정구역의 제한 고시를 폐지하여 디지털광고물의 표시(설치)가 용이하도록 지원해야 합니다. 특히 중소 옥외광고사업자를 위해 교육 지원이 절실합니다. 차세대 전문인력을 확보하기 위해 체계적으로 교육할 수 있는 시설 및 운영기관이 필요하고요. 중소 옥외광고사업자의 불법 행위 근절을 위한 관계법령 등 교육과정 설치가 필요합니다.”(업계 3)

“단기적으로 새로운 기술이 있어도 기존 옥외광고사업자의 경우 접근하기가 어려워요. 디지털 옥외광고에 대한 교육이 절실합니다. 4차산업의 기본인 디지털 옥외광고산업의 경우는 이미 정부를 포함하여 산학과 모두 디지털 옥외광고산업의 육성과 시범사업 확대를 강조하고 있습니다." (업계 2)

“현재의 옥외광고산업 종사자를 대상으로 기초 및 심화 과정의 이원화가 필요해요. 우선 기초과정의 경우 입사 초년부터 대리차까지의 직원들의 대상으로 하는 광고 윤리, 옥외광고물 법규의 이해, 옥외광고산업동향 및 발전 방향, 불법광고물 정비 등을 교육하고, 심화 과정의 경우 최근 신기술과 관련한 도입 관련 법규, 신기술 접목 해외 옥외광고 동향 파악, 벤치마킹 사례 등을 교육하면 좋을 듯 합니다.”(학계 3)

\section{5. 결론 및 제언}

본 연구에서는 코로나19로 인해 경제 상황이 악화된 옥외광고 중소사업자들에게 뉴노멀 환경에 맞는 지원책과 디지털 옥외광고산업 진흥책을 알아보기 위해 전문가 심층 인터뷰를 실시하였다. 연구결과 코로나 19 로 인해 옥외광고 중소사업자가 더 큰 피해를 보고 있어 정부의 지원이 시급하다. 장기적으로 옥외광고산업이 발전하기 위해서는 중소사업자들이 영업하기 좋은 환경 조성과 새로운 기술 도입이 필요하다. 그러나 디지털 옥외광고산업의 전환을 위해선 기존 중소사업자의 입장을 반영한 현실적인 지원과 육성 정책이 우선이다.

디지털 옥외광고산업 진흥을 위한 중소사업자 지원 방안에 있어서 단기적 지원 방안과 장기적 지원 방안이 필요하다. 우선, 단기적 지원 방안으로 신소재·신매체 개발 지원, 디지털 옥외광고 교육, 공공목적 디지털 옥외광고물 운영사업자 선정 참여 기회 제공이 필요하다. 예컨대 새로운 매체 방안으로 2021 칸느라이온즈 아웃도어 부문 그랑프리를 수상한 셔텨광고(Shutter Ads)를 들 수 있다. 이 광고에서는 하이네켄 브랜드가 문을 닫은 
술집의 셔터를 옥외광고로 활용하여 자영업자에게 실제적인 도움을 주었듯이 새로운 옥외매체를 개발하면 옥외광고 중소사업자들에게 도움을 줄 수 있을 것이다. 또한 옥외광고 활성화를 위해선 디지털 콘텐츠 개발이 우선되어야 한다. 대표적으로 서울역 팡장에 전시된 줄리언 오피의 <걸어가는 사람들> LED 영상이나 삼성동 코엑스와 부산 현대모터스튜디오에 전시된 영국 Universal Everything 그룹의 작품들은 옥외광고의 가치를 높이는 디지털 콘텐츠라 할 수 있다. 이러한 디지털 콘텐츠를 국내외 작가를 통해 유치한다면 중소사업자의 비즈니스 모델 개발에 도움을 줄 수 있을 것이다. 이러한 디지털 옥외광고산업 진흥을 육성하기 위해서는 실무 중심의 옥외광고 중소사업자 교육이 필요하며, 특히 실질적인 교육을 받을 수 있는 옥외광고 전문 교육기관이 신설되어야 한다. 옥외광고 중소사업자 개설방식은 기초 과정과 심화 과정을 구분하여 실행하는 것이 효과적이다. 기존 교육에서는 기존의 옥외광고물 지식을 습득할 수 있는 과정을 진행하고, 심화 과정에서는 최근 디지털 신기술을 활용한 옥외광고 사례와 제작 및 관련 법규 등을 설명하여 실무자의 눈높이 맞는 교육이 실시되어야 한다. 디지털 옥외광고 교육은 신유형 광고 교육(AR, $\mathrm{VR}, \mathrm{AI}$, 클라우드 등), 디지털 광고 표시 관련 분쟁·불법 행위 근절을 위한 관계 법령 교육, 특허 등 지식재산권 관리 방법 등 중소사업자가 원하는 시의적인 교육 내용으로 구성되어야 한다.

두 번째 장기적인 지원방안으로 새로운 사업 영역을 찾을 수 있도록 신기술 개발을 위한 관련 법 규제(네거티브 규제) 완화, 공공 디지털 옥외광고물 사업자 입찰 참여 방식의 완화, 신매체·신기술 전환을 위한 대형사업자와 업무 제휴 등이 필요하다. 세부적으로 살펴보면, 관련 법 규제 완화를 위해선 혼재되어 있는 관련 부처 통합이 필요하다. 부처 간 통합을 통해 정부 기관, 지자체, 중소광고사업자 및 관련 기관, 학회 등이 진화된 옥외광고산업 발전 협의체를 구성하여 디지털 옥외광고산업 발전을 위한 가이드라인을 제시하여야 한다. 중소사업자의 입찰 규제 완화를 통해 공공디지털 옥외광고물의 입찰 참여기회를 확대하여 균형있는 옥외광고시장을 만들어야 할 것이다. 또한 중소사업자들이 해결할 수 없는 투자 사업과 시장 분석, 광고효과 분석 등에 대한 대형사업자 업무 제휴가 필요하며, 특히 중소사업자에게도 옥외광고 기술을 해외 시장에 수출할 수 있는 플랫폼 운영사업지원 제도도 마련되어야 한다.

이상 본 연구에서는 코로나19 이후 뉴노멀 시대의 디지털 광고산업 진흥 방안을 중소사업자 입장에서 분석했다는 점에서 시의적인 연구라 할 수 있다. 그러나 전문가 심층 인터뷰로 이루어져 실제 중소사업자의 객관적인 검증을 거치지 않아 신뢰도가 떨어질 수 있어 연구의 한계로 지적된다. 향후 연구에서는 실제 중소사업자를 대상으로 현재 분석된 내용을 바탕으로 실증 분석이 이루어져야 할 것이다.

\section{6. 감사의 글}

본 연구는 한국지방재정공제회 부설 한국옥외광고센터의 지원으로 수행되었습니다.

\section{References}

[1] 2020 Broadcasting and Communication Advertising Cost Survey Report, Ministry of Science and ICT, KOBACO, pp.134-141, (2020)

[2] 2020 Broadcasting and Communication Advertising Cost Survey Report, Ministry of Science and ICT, KOBACO, 
p.172, (2020)

[3] 2020 Advertising Industry Survey, Ministry of Culture, Sports and Tourism, p.153, (2020)

[4] Mingu Yeo, Hanjun Ko, A Study on Applicability of Programmatic Advertising in Digital Signage: Focused on Media Context Information, The Korean Journal of Advertising and Public Relations, (2018), Vol.20, No.4, pp.274-303, DOI: 10.16914/kjapr.2018.20.4.274

[5] Honggeun Jin, Jaeyoung Kim, Research for the Activation of Outdoor Advertising Industry Advertisers, Agencies Focused on Perceptions, The Korean journal of advertising and public relations, (2012), Vol.14, No.3, pp.33-65, UCI: G704-001035.2012.14.3.004

[6] Yong-seok Cheon, Searching for a Direction for Activation of Digital Signage in the Smart Advertising Industry, Information and Communication Broadcasting Policy, (2014), Vol.26, No.14, pp.1-22.

[7] Kwang-Seok Han, The Role of Government for the Development of Domestic Outdoor Advertising, Journal of OOH Advertising Research, (2014), Vol.11, No.1, pp.31-61, UCI: G704-002211.2014.11.1.004

[8] Kwang-Seok Han, Woon-Han Kim, Hong-Geun Jin, Jun-Jun Jeong, Hye-Kyung Jeon, A Plan to Strengthen the Role of the Outdoor Advertising Center for Promotion and Fostering of the Outdoor Advertising Industry, Korea Outdoor Advertising Center Research Report, pp.82-84, (2018)

[9] Won-Bae Ji, The urgency of preparing a legal system for the promotion of the advertising industry, Special Session A of the Korean Advertising Society Fall Conference, Korean Advertising Society, pp.21-40, (2020), October 30, Seoul, Korea.

[10] Hyun Park, Promotion of the outdoor advertising industry and a win-win plan for the industry, 2018 Korea OOH Advertising Society Conference, Korea OOH Advertising Society, pp.59-70, (2018), April 20, Seoul, Korea

[11] Heebok Lee, Yoochul Cha, Sihun Lee, Plan to Improve the Regulations on Outdoor Advertising: Focusing on LED Placard and Support of Small and Medium Business Operators, Advertising Research, (2015), No.106, pp.73-110, DOI: $10.16914 /$ ar.2015.106.73

[12] R. V. Kozinets, The Field Behind the Screen: Using Netnography for Marketing Research in Online Communities, Journal of Marketing Research, (2002), Vol.39, No.1, pp.61-72, DOI: 10.1509/jmkr.39.1.61.18935

[13] R. V. Kozinets, Netnography: Doing Ethnographic Research Online, SAGE publications, pp.31-58. (2010) 